\title{
Classification of fruit trichomes in cucumber and effects of plant hormones on type II fruit trichome development
}

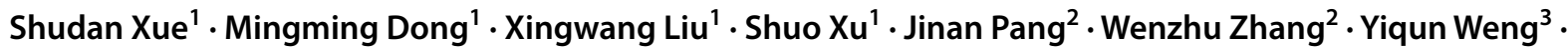 \\ Huazhong Ren ${ }^{1}$
}

Received: 3 July 2018 / Accepted: 3 September 2018 / Published online: 17 September 2018

(C) The Author(s) 2018

\begin{abstract}
Main conclusion Cucumber fruit trichomes could be classified into eight types; all of them are multicellular with complex and different developmental processes as compared with unicellular trichomes in other plants.
\end{abstract}

\begin{abstract}
The fruit trichomes or fruit spines of cucumber, Cucumis sativus L., are highly specialized structures originating from epidermal cells with diverse morphology, which grow perpendicular to the fruit surface. To understand the underlying molecular mechanisms of fruit trichome development, in this study, we conducted morphological characterization and classification of cucumber fruit trichomes and their developmental processes. We examined the fruit trichomes among 200 cucumber varieties, which could be classified into eight morphologically distinct types (I-VIII). Investigation of the organogenesis of the eight types of trichomes revealed two main developmental patterns. The development of glandular trichomes had multiple stages including initiation and expansion of the trichome precursor cell protuberating out of the epidermal surface, followed by periclinal bipartition to two cells (top and bottom) which later formed the head region and the stalk, respectively, through subsequent cell divisions. The non-glandular trichome development started with the expansion of the precursor cell perpendicularly to the epidermal plane followed by cell periclinal division to form a stalk comprising of some rectangle cells and a pointed apex cell. The base cell then started anticlinal bipartition to two cells, which then underwent many cell divisions to form a multicellular spherical structure. In addition, phytohormones as environmental cues were closely related to trichome development. We found that GA and BAP were capable of increasing trichome number per fruit with distinct effects under different concentrations.
\end{abstract}

Keywords Cucumis sativus L. · Fruit trichomes $\cdot$ Fruit spines $\cdot$ Organogenesis $\cdot$ Plant hormones

Electronic supplementary material The online version of this article (https://doi.org/10.1007/s00425-018-3004-9) contains supplementary material, which is available to authorized users.

Yiqun Weng

yiqun.weng@ars.usda.gov

$\triangle$ Huazhong Ren

renhuazhong@cau.edu.cn

1 Beijing Key Laboratory of Growth and Developmental Regulation for Protected Vegetable Crops, College of Horticulture, China Agricultural University, Beijing, China

2 Tianjin Derit Seeds Co. Ltd, Tianjin, China

3 USDA-ARS Vegetable Crops Research Unit, Horticulture Department, University of Wisconsin-Madison, Madison, USA

\author{
Abbreviations \\ BAP 6-Benzylaminopurine \\ CTK Cytokinin \\ GA Gibberellin \\ JA Jasmonic acid
}

\section{Introduction}

Cucumber (Cucumis sativus L.) is an economically important crop cultivated worldwide (Huang et al. 2009). The trichomes on cucumber fruits, or fruit spines, are highly specialized structures originating from the epidermal cells. Like those in many other plant species, the cucumber fruit trichomes are diverse in shape, size, structure, and their capabilities to secrete. (Yamamoto et al. 1989; Li et al. 2013; Chen et al. 2014). Trichomes may play 
important roles in protecting plants from environmental stresses such as heat, low temperature, high UV, and insect herbivory (Wagner 1991; Werker 2000). Cucumber fruit spines are fruit-quality attributes important for fruit commercial value ( $\mathrm{Li}$ et al. 2013). For example, fruits of most fresh market cucumbers cultivated in China have dense and large, white spines preferred by the consumers. The North American processing cucumbers (pickles) usually have a few large spines on each fruit, whereas European greenhouse (English) or Mediterranean (beit alpha or mini) cucumbers have no visible trichomes, which may be easy for cleaning, packing, or keep less pesticide residues (Wang et al. 2007; Yang et al. 2009; Pan et al. 2015). As such, it is of both theoretical and applied interests to understand the organogenesis, development, and genetics of trichome development in cucumber.

In cucumber, fruit trichome morphology varies widely between varieties or even individual plants, but limited studies have been conducted. By examining one cucumber variety, Chen et al. (2014) identified two types (I and II) of fruit trichomes. Several glabrous (gl) mutants have been identified in cucumber including csgll (syn. mict, tbh), csgl2, and $\operatorname{csgl3}$ (syn. tril), and the respective genes play important roles in trichome initiation or development (Yang et al. 2011; Chen et al. 2014; Li et al. 2015; Zhao et al. 2015; Pan et al. 2015; Cui et al. 2016; Liu et al. 2016; Wang et al. 2016; Zhang et al. 2016;). However, a systematic investigation of fruit trichomes is lacking.

Based on cell numbers, trichomes can be classified as either unicellular or multicellular. There is evidence that different types of trichomes are formed by different developmental programs with multiple evolutionary origins (Serna and Martin 2006). For example, Arabidopsis trichomes and cotton fibers are unicellular, while the trichomes of cucumber, tobacco, tomato, and snapdragon belong to multicellular types. In Arabidopsis, trichome development undergoes several stages including expansion of committed precursor cell, stalk growing perpendicular to the epidermal plane, formation of branches, expansion of stalk and branches, emerging of pointed tips, and numerous papillae appearing on outer surface (Hülskamp et al. 1994; Szymanski et al. 1998). Cotton fiber development has four overlapping stages: initiation, elongation, secondary wall deposition, and maturation (Qin and Zhu 2011; Yang and Ye 2013). Tobacco leaves have two discrete types of multicellular trichomes with different lengths of stalk (Akers et al. 1978). Tomato has seven types of multicellular trichomes that are glandular (types I, IV, VI, and VII) or non-glandular (types II, III, and V) (Luckwill 1943; Kang et al. 2010; Tissier 2012). In cucumber, Chen et al. (2014) examined the development of non-glandular cucumber trichomes in a North China type variety. Overall, our knowledge on the developmental processes of multicellular trichomes is still very limited.
Plant trichome initiation and morphogenesis are influenced by diverse developmental and environmental cues. Phytohormones such as gibberellins (GA), salicylic acid (SA), jasmonic acid (JA), and cytokinin (CTK) have been shown to modulate trichome development. For example, in Arabidopsis, GA, CTK, and JA have positive effects on trichome production, whereas SA influences trichome production negatively (Chien and Sussex 1996; Telfer et al. 1997; Perazza et al. 1998; Traw and Bergelson 2003; Maes et al. 2008; Gan et al. 2006, 2007). In tomato, cytokinin (6-benzylaminopurine, BAP). $\mathrm{GA}_{3}$ and $\mathrm{JA}$ were shown to stimulate trichome initiation with distinct effects on different types of trichomes (Boughton et al. 2005; Maes and Goossens 2010). However, the effects of those phytohormones on trichome formation in cucumber have not been examined. Whether the effect of phytohormones on cucumber fruit trichome is conserved or not will enrich our knowledge about trichome formation in diverse plant species.

Thus, the objectives of the present study were to examine fruit trichomes among diverse cucumber varieties and conduct systematic classification, which will provide a start point in understanding the molecular mechanisms of fruit trichome development in cucumber. We investigated the fruit trichome micromorphology of 200 cucumber varieties, which could be grouped into eight types. For each group, we investigated the organogenesis of fruit trichomes and found two main types of trichome development patterns in cucumber. We also examined the effect of GA and BAP on fruit trichome development.

\section{Materials and methods}

\section{Plant materials and microscopic investigations}

Two hundred cucumber varieties including two glabrous mutants, $\operatorname{csgll}$ and $\operatorname{csgl} 3$, with different morphological structure of fruit trichomes were used for the initial observation and classification ( $\mathrm{Li}$ et al. 2015; Zhao et al. 2015; Chen et al. 2014; Pan et al. 2015). Information of these varieties is provided in Suppl. File S1 and typical images are shown in Fig. 2. Five plants per variety and four fruits per plant were used for investigation. Cucumber plants were grown in the greenhouse under natural photoperiodic condition. The temperature in the greenhouse was $25-30{ }^{\circ} \mathrm{C}$ during the day and $18-25{ }^{\circ} \mathrm{C}$ during the night with $30-85 \%$ relative humidity.

A light microscope or a scanning electron microscope (SEM) was employed to examine trichomes at different developmental stages when the ovary or pollinated young fruits were $0.2,0.4,1.8,3,4.3$, and $6.5 \mathrm{~cm}$ in length. For SEM, epidermis including trichomes from each sample were fixed, washed, post-fixed, dehydrated, coated, and, finally, observed using a Hitachi S-4700 scanning electron 
microscope following Chen et al. (2014). For light microscopy, epoxy resin semi-thin sectioning was performed to observe trichomes that were not visually discernable to a naked eye. Similar to SEM, the epidermis including trichomes of young fruit with $0.2,0.4,1.8,3$, and $4.3 \mathrm{~cm}$ in length was fixed in glutaraldehyde and rinsed with phosphate buffer, post-fixed with Hungry acid, washed in phosphate buffer, dehydrated through an acetone series, and, finally, embedded in Spurr's resin. Thin sections were prepared with a LEICA UC6I microtome (Chen et al. 2014).

\section{Treatments with phytohormones}

One variety 6102 (Fig. 2), which is a South China fresh market type cucumber with moderate number of Type II fruit trichomes, was used to investigate the effects of two phytohormones on trichome development. For each hormone, three concentrations were tested: 0 (water, control), 250, 500, or $2000 \mu \mathrm{M}$ for GA; 0 (water, control), 25, 50, and $100 \mu \mathrm{M}$ for BAP. When the cotyledons were fully expanded and the first true leaf was just emerged, each seedling was sprayed every other day until it reached 5-true-leaf stage. Then, each plant was sprayed twice per week until fruit set. There were four replications (plants) for each treatment.

For each treatment, the number of Type II trichomes was counted on the ovary on the day of anthesis or on the young fruits 4 days after pollination. Duncan's test $(P<0.05)$ was performed to determine if the means were significantly different between the control and the treatment.

\section{Results}

\section{Morphological classification of cucumber fruit trichomes}

A trichome is a distinct feature of plant species. Trichomes vary considerably in number, color, and size (length, width). By investigating the fruit trichomes of 200 cucumber varieties from different regions and market classes (Suppl. File S1), we found that all cucumber fruit trichomes were multicellular, but they could be classified in eight types: I through VIII (Fig. 1), each of which had unique structure and morphology.

Among the eight types of fruit trichomes, two (I and VI) were glandular and six (II, III, IV, V, VII, and VIII) were non-glandular (Fig. 1). Type I trichomes were found on the fruits of all cucumber varieties examined except the two glabrous mutants ( $c s g l l$ and $c s g l 3$ ). Type I trichomes were frequently distributed all over the fruit surface which were consisted of a short uniseriate stalk with 3-4 cells and a four- or five-celled head region with glandular functions. This glandular trichome (named bloom trichome) was believed to be associated with production of mineral elements and cuticle formation on the surface of the cucumber fruits (Yamamoto et al. 1989; Samuels et al. 1993). Type II trichomes were also identified in most cucumber varieties examined which had a spherical multicellular base and a long trichome stalk composed of 6-8 cells, and ended with a pointed tip (Fig. 1). As compared with Type II trichomes, a Type III trichome contained a much shorter stalk that was composed of 3-6 cells and ended with a pointed tip above a conical trichome base. Type IV trichomes were similar to Type II ones in their appearances, but each had a shorter stalk and a smaller base. Type $\mathrm{V}$ trichomes had the appearance of a pyramid without noticeably slender stalk and swollen base (Fig. 1). Type VI glandular trichomes were rarely observed; each contained similar four- or five-celled gland on the head, but had longer stalk cells as compared with Type I trichomes. Trichomes of Type VII and VIII were only found on the glabrous mutant csgll (syn. mict, tbh) (Chen et al. 2014; Li et al. 2015; Zhao et al. 2015) that were invisible to naked eyes. Under a scanning electron microscope (SEM), these trichomes did not have flattened multicellular bases. A Type VII trichome was comprised of 6-10 cells stacked vertically without a pointed tip, and a Type VIII trichome had some irregular branches without a pointed cell (Fig. 1).

The fruit trichomes varied widely in the number and size of cells. We measured the horizontal maximum width (the diameter of the base or the widest section of the trichome), and the length of the whole trichome in the longitudinal direction of the different types of trichomes. The data are presented in Table 1.

Trichomes were not only formed on fruits, but also on other organs. Interestingly, fruit trichomes were morphologically diverse compared to those on other organs such as the leaf, stem, and tendril. Among the almost 200 varieties examined, the leaf, stem, and tendril only had three types of trichomes: one non-glandular and two glandular which were morphologically similar to types I, II, and VI, respectively (Suppl. Fig. S1). This may suggest that trichome development may be organ specific.

The classification of the eight types of fruit trichomes among the 200 varieties seemed to be associated with visible fruit epidermal features, but showed no correlation with fruit length, size, or fruit skin color. It was worth noting that trichome type had distinct relationship with the existence of tubercules. Tubercules are derived from several layers of cells that lie near the trichome base with an expanded structure (Yang et al. 2014, 2018) (Fig. S2). Typically, if a fruit had smooth appearance without tubercules, the fruit had mainly types I, IV, or V trichomes; if a fruit had tubercules, it had mainly types I, II, or III trichomes (Fig. 2, Fig. S2 and Suppl. File S1). Type I trichomes were the most abundant that were found in almost all the 200 cucumber varieties examined. Most fruits had two types of trichomes on the 
Fig. 1 Morphological characterization of eight (I-VIII) types of trichomes on cucumber fruits. Fruit surface: Type I (a), fruit transverse section: Type II (b); Type III (c); Type IV (d); Type V (e); Type VII and VIII (f). Bar $=500 \mu \mathrm{m}($ II-IV) $100 \mu \mathrm{m}(\mathbf{V}) ; 20 \mu \mathrm{m}(\mathbf{V I})$; or $5 \mu \mathrm{m}$ (I, VII, and VIII)
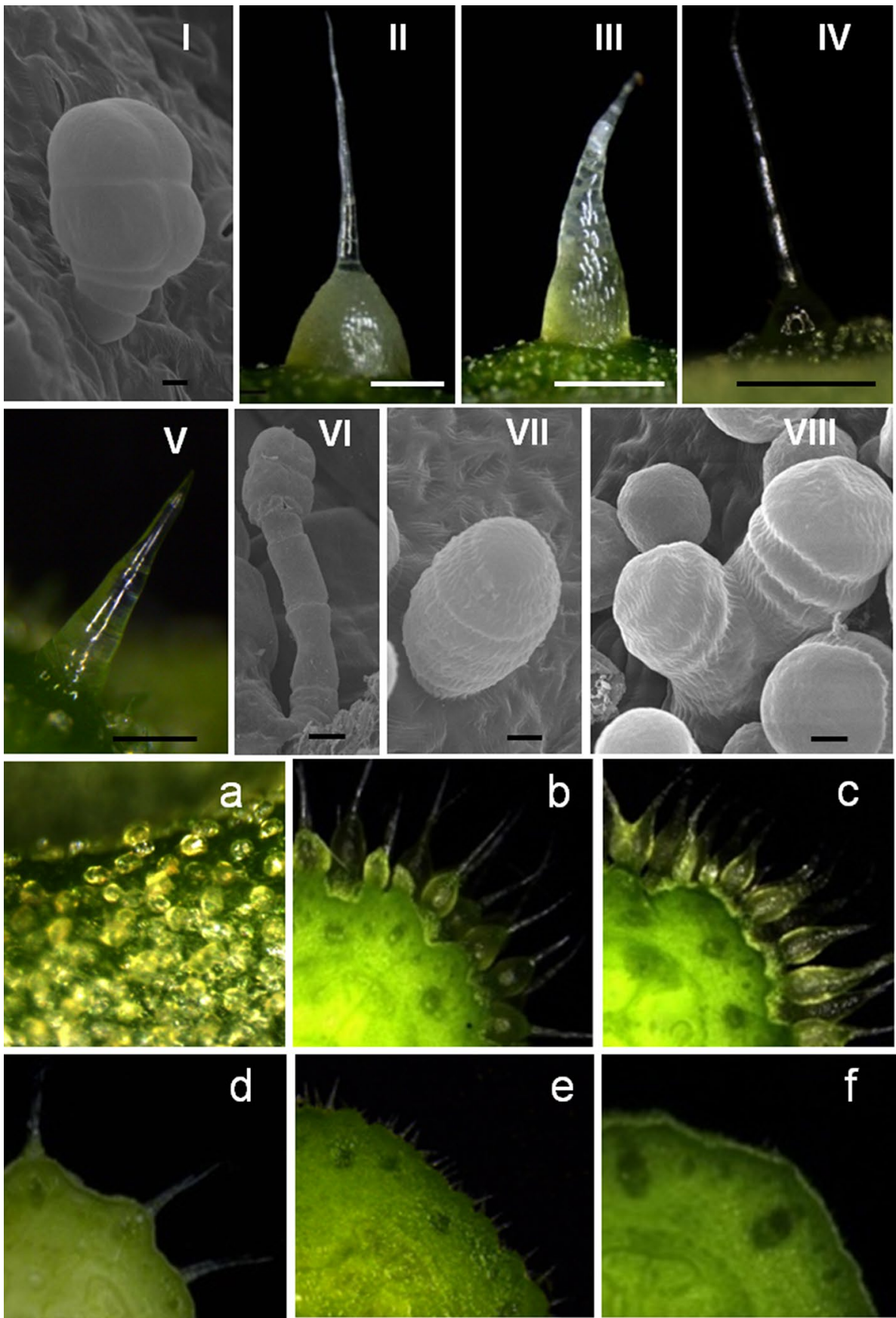

e

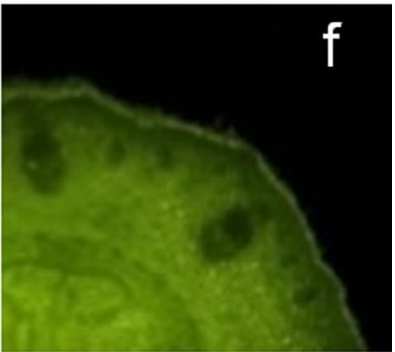

Table 1 Size of eight types of fruit trichomes in terms of maximum longitudinal length and horizontal width)

\begin{tabular}{|c|c|c|c|c|c|c|c|c|}
\hline Trichome types & I & II & III & IV & V & VI & VII & VIII \\
\hline n) & $48.52 \pm 11.9$ & $2666.2 \pm 352.4$ & $2661.8 \pm 171.3$ & $1377.4 \pm 153.9$ & $657.2 \pm 85.6$ & $170.3 \pm 20.0$ & $20.0 \pm 6.7$ & $32.6 \pm 8$ \\
\hline Width $(\mu \mathrm{m})$ & $32.0 \pm 4.8$ & $694.8 \pm 84.3$ & $345.9 \pm 20.5$ & $159.7 \pm 9.7$ & $59.8 \pm 5.5$ & $38.2 \pm 3.9$ & $15.8 \pm 1.4$ & $17.6 \pm 3.2$ \\
\hline
\end{tabular}

Data are means \pm SD (standard deviation) of 30 trichomes from the surface of different fruits at anthesis 


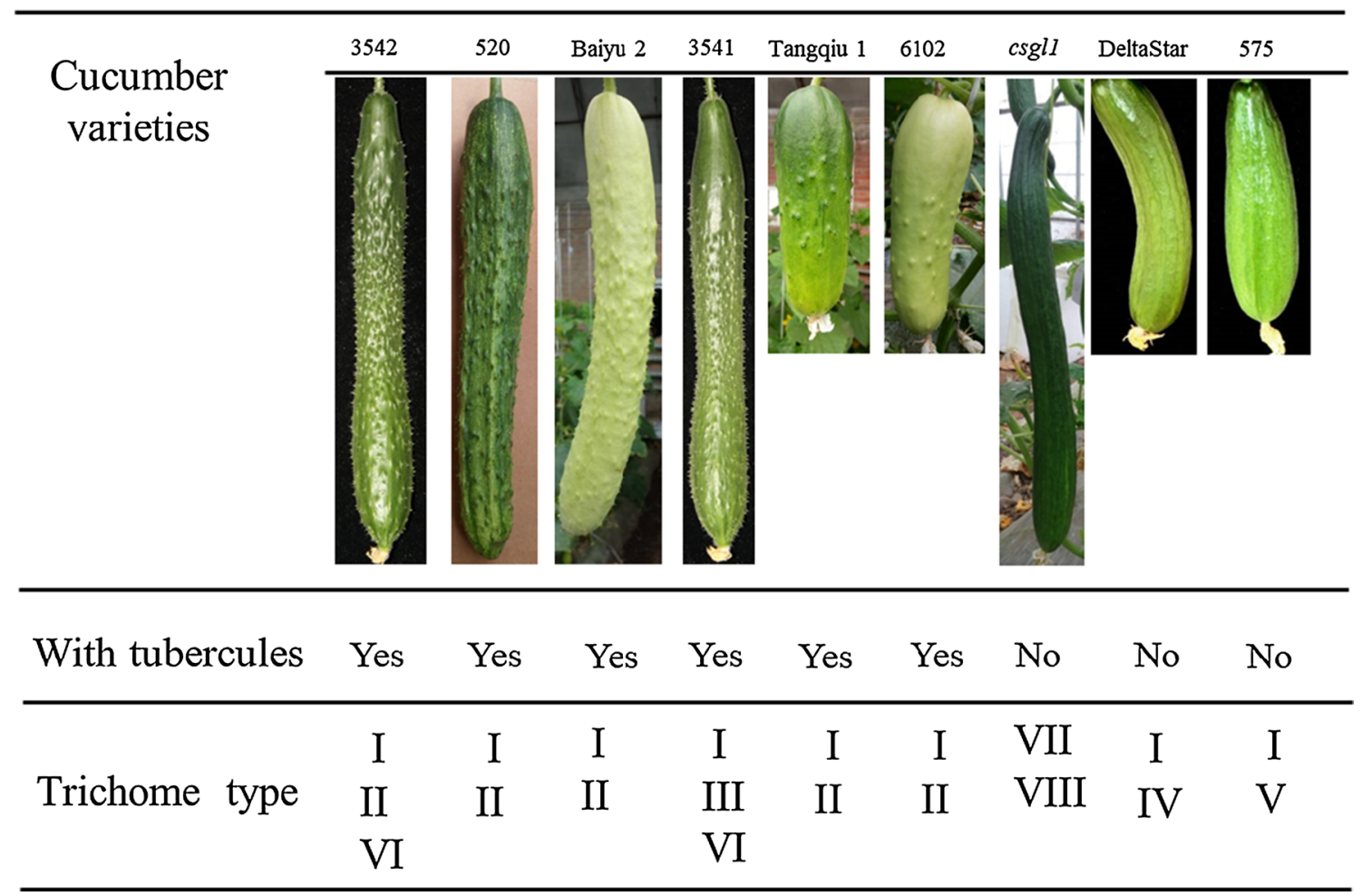

Fig. 2 Classification of fruit trichome types in representative cucumber varieties with diversity in fruit color or length. The types of trichomes seem to be correlated with visible fruit epidermal features (the existence of tubercules, Suppl. Fig. S2). Typically, tuberculated fruits $(3542,520$, Baiyu 2, 3541, Tangqiu 1, 6102) have Types I, II, or III trichomes; fruits with smooth appearance without tubercu-

cuticular layer of the fruit, but, interestingly, we found some possessed three types of trichomes including two glandular types and one non-glandular type (Fig. 2).

\section{Comparative analysis of multicellular fruit trichome development}

The multicellular cucumber fruit trichomes have different developmental patterns from unicellular trichomes in other plant species. We examined the developmental processes of all eight types of fruit trichomes under a microscope, and the results for Type I (glandular trichome) and Type II trichomes are illustrated in Figs. 3 and 4, respectively; those for the rest are provided as supplemental data (Fig. S3 a-r). Type I trichome development was initiated from a trichome precursor cell protuberating on the surface of the epidermis (Fig. 3a) followed by expansion (Fig. 3a, b) which underwent a periclinal bipartition to two cells (Fig. 3c). This was followed by cell divisions to form the head region and the stalk (Fig. 3d-g). The developmental pattern of the Type VI glandular trichomes was similar to Type I ones with some minor differences in the stalk length. les (DeltaStar, 575) have mainly types I, IV, or V trichomes. Type I fruit trichomes are the most abundant that are found in almost all cucumber varieties examined. Some varieties possess three types of trichomes including two glandular types (I and VI) and one non-glandular type (II)

During the development of the non-glandular Type II trichomes, the precursor cell expanded perpendicularly to the epidermal plane followed by cell periclinal divisions to form a stalk consisting of 5-7 rectangle cells and a pointed apex cell (Fig. 4a). The base cell started anticlinal bipartition to two cells (Fig. 4b), and then, the base underwent multiple rounds of cell divisions to form a multicellular spherical structure (Fig. 4c-i). Similar patterns were observed in the development of the non-glandular Type III trichomes, which included shorter stalk and longer base. An especially noticeable feature of the Type III trichomes was the division of base cell to form a conical structure (Suppl. Fig. S3 a-g). Type IV trichomes underwent initiation and division to form a multicellular stalk, and then, the base cell divided into multicellular structure that was similar to but smaller than Type II trichomes (Fig. S3 h-j). Type V trichomes eventually developed into a unique pyramid structure without noticeable slender stalk and swollen base (Fig. S3 k-n). Type VII trichomes started with one trichome cell expansion followed by several cell periclinal divisions, and multiple cells stacked together in line without a pointed tip (Fig. S3 o-q). The developmental processes of Type VIII trichomes were largely similar to those of Type VII, but 
Fig. 3 Development of type I glandular trichomes. Trichome development starts with a trichome precursor cell that protuberates on the surface of epidermis (a). After cell expansion of the precursor cell (b), it bipartition to two cells (c) followed by cell division to form the head region and the stalk $(\mathbf{d}-\mathbf{g})$. Scale bar $=10 \mu \mathrm{m}$

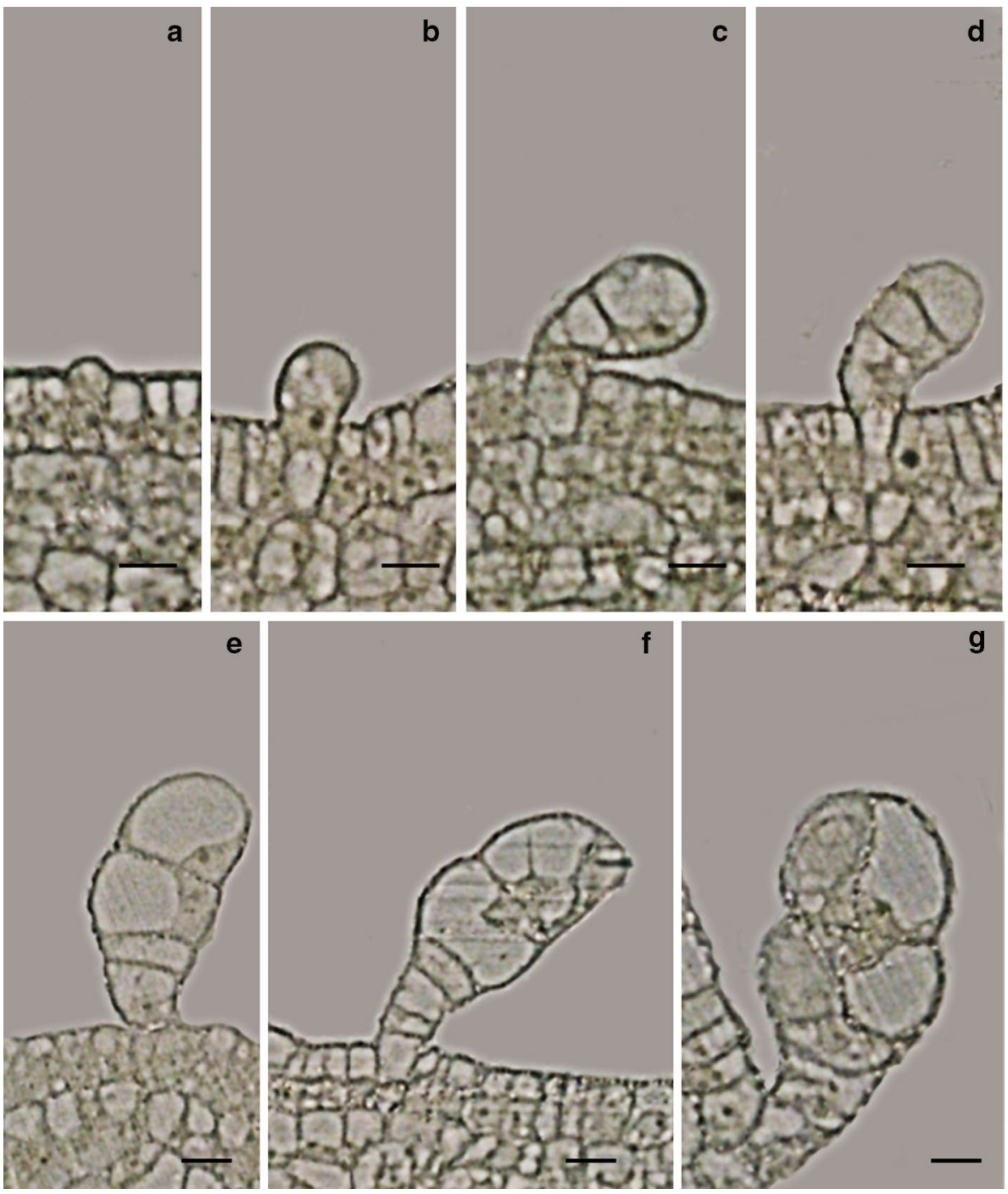

Type VIII trichomes had an additional branch formation at the late stages (Fig. S3 o, p, r).

All non-glandular fruit trichomes had a senescence phase in which the apical region turned white or brown first followed by other parts of the trichome in the order from the top to bottom to lose the green color and turn to white or brown in color.

\section{Effects of exogenous hormones on development of Type II fruit trichomes}

We examined the effects of two plant hormones: 6-benzylaminopurine (BAP, a synthetic cytokinin) and gibberellin $\left(\mathrm{GA}_{3}\right)$ on epidermal differentiation and fruit spine development. In our preliminary study, no effects were found by the application of the two hormones on the size (length or width) of fruit trichomes (Fig. 5b, d), but we, indeed, found that they affected trichome numbers per fruit. Thus, plants were treated with three concentrations of $\mathrm{GA}_{3}$ or BAP, and the number of Type II trichomes was counted on the ovary on the day of anthesis or on the young fruits at 4 day postanthesis (Type I trichomes were also present on the fruit but not counted due to difficulty in visual counting). The results are illustrated in Fig. 5a, c. As compared with the control (no $\mathrm{GA}_{3}$ ), application of $250 \mu \mathrm{M} \mathrm{GA}$ markedly increased the trichome numbers (Fig. 5a). On the other hand, trichome number increased progressively with the increase of BAP concentrations, by up to $33 \%$ and $57 \%$, respectively, which remained almost unchanged with low concentration of $25 \mu \mathrm{M}$ (Fig. 5c). This suggested that both BAP and GA are able to stimulate cucumber fruit trichome formation, which is concentration-dependent. 
Fig. 4 Development of type II multicellular non-glandular trichomes. a Trichome precursor cell experienced: expand perpendicular to the epidermal plane, cell periclinal division, with a structure of about eight cells uniseriate line. b Single basal cell began bipartition to two cells. c-i Base undergoes many cell division to form multicellular spherical structure. Scale bars $=50 \mu \mathrm{m}(\mathbf{a}-\mathbf{e})$, $500 \mu \mathrm{m}(\mathbf{f}-\mathbf{i})$
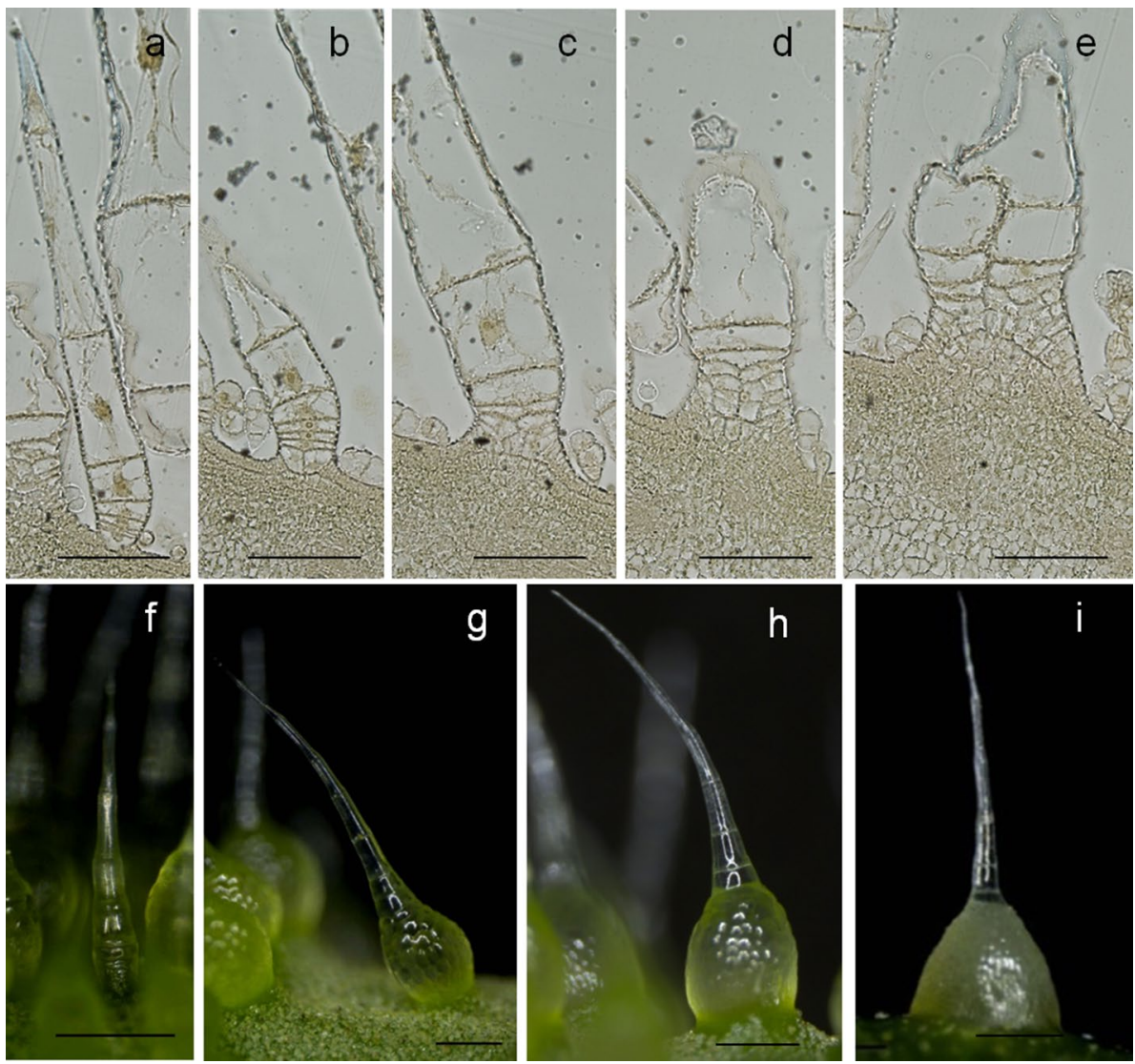

\section{Discussion}

In the Cucurbitaceae family, fruit trichomes, like many other morphological features, are very diverse, which vary from unicellular to multicellular, glandular or non-glandular, conical to elongated, and with or without a flattened base (Ali and Al-Hemaid 2011). In the present study, we examined the fruit trichomes from 200 cucumber varieties of different market classes, geographic regions, or with different taxonomic status (Suppl. File S1). Based on the morphological features, eight types of trichomes, types I-VIII, were recognized (Fig. 1). Most varieties had two types of trichomes (types I+II) (Fig. 2), which was also described in the previous studies (Chen et al. 2014; Liu et al. 2016). For the first time, we identified a few cucumber varieties with three types of fruit trichomes including one non-glandular and two glandular trichomes (I+ II + VI or I+ III + VI) (Fig. 2). This is also the first report of Type VI glandular trichomes with a multicellular stalk (7-8 cells), a neck cell, and a multicellular head (4-5 cells), which was different from Type I glandular trichomes. Moreover, tubercules as fruit epidermal feature were found to be correlated with trichome types. If a fruit had smooth appearance without tubercules, there were mainly types I, IV, or V trichomes; if fruit covering with tubercules, there were mainly types I, II, or III trichomes.
Of the eight types of fruit trichomes, types I and VI were glandular and the rest were non-glandular. The type I glandular trichomes may be responsible for the accumulation of mineral elements and cuticle formation (Yamamoto et al. 1989; Samuels et al. 1993), but the secretory process and the mechanisms of secretion are not clear yet. In some cucurbit crops such as the Styrian oil pumpkin and melon, there are studies on the dynamic process of secretory release from their glandular trichomes (Kolb and Muller 2004; Sarria et al. 2010). These secretory trichomes have similar morphology and structure as the cucumber type I glandular trichomes of cucumber. Thus, it is possible that the secretory process of type I cucumber glandular trichomes may be similar.

We examined the organogenesis of all eight types of fruit trichomes, which seemed to be complex for the multicellular trichomes. Nevertheless, all trichomes could be classified into two groups based on the developmental processes (Figs. 3 and 4, Suppl. Fig. S3). For the first group that included types II, III, IV, and V non-glandular trichomes, the trichome started from a precursor cell undergoing trichome cell initiation and expansion, followed by cell periclinal division to form a stalk that was consisted of many cells ended with a pointed apex cell; then, the base cell from bipartition to many cell divisions to form a multicellular structure. For 

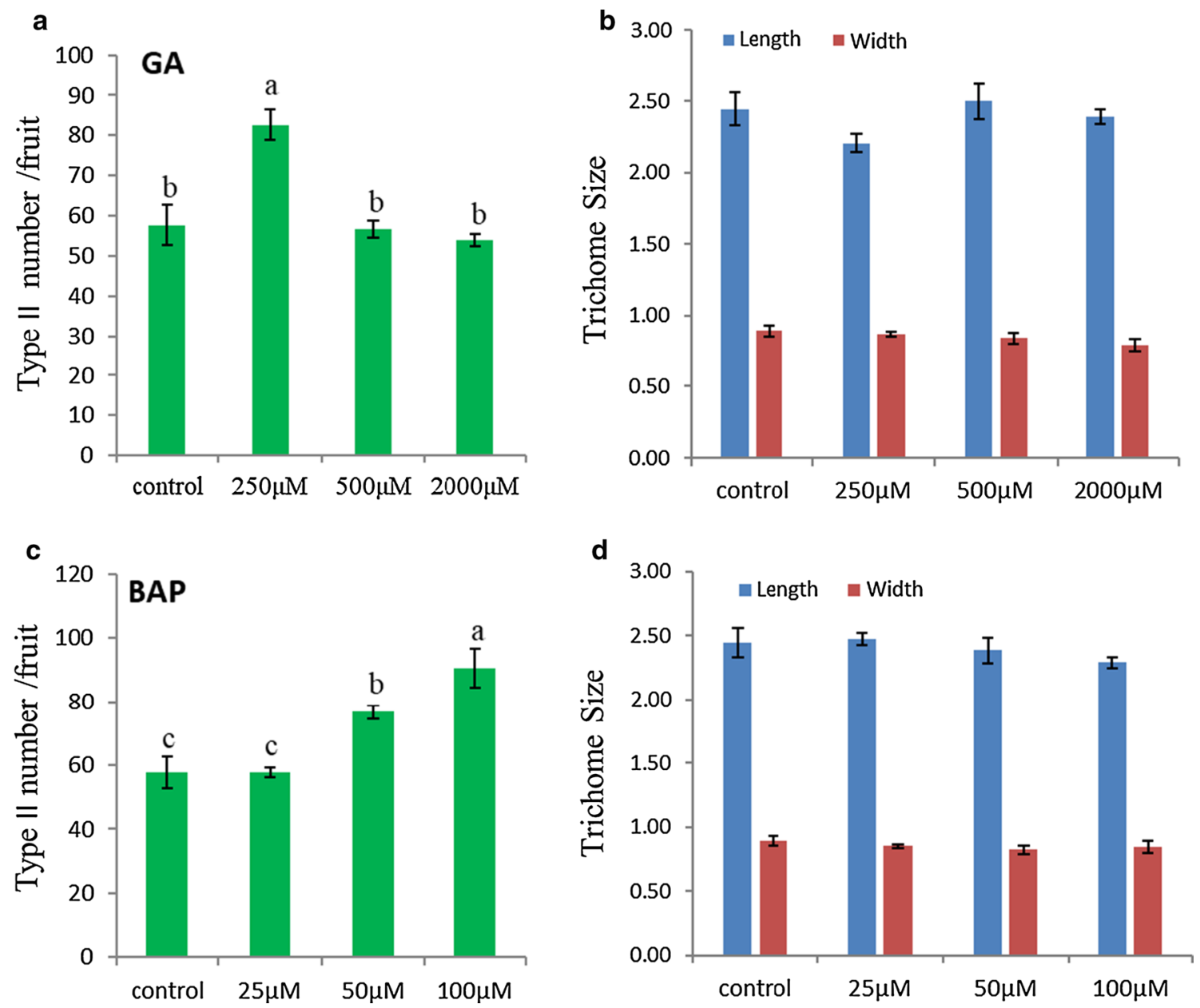

Fig. 5 Effects of gibberellin $\left(\mathrm{GA}_{3}\right)$ and cytokinin (6-benzylaminopurine or BAP) on the Type II fruit trichomes. Effects of $\mathrm{GA}_{3}$ on number per fruit (a) and the size of fruit trichomes either length or width (b). Effects of BAP on number per fruit (c) and the size of fruit tri-

chomes either length or width (d). Data are the means of three replicates with standard errors shown by vertical bar. Different letters shown in the error bars indicate significant differences among control and treatments according to Duncan's test $(P<0.05)$

the second group (types I and VI glandular trichomes), the developmental process included protuberating of one trichome precursor cell, expansion, bipartition followed by cell divisions to form the head region and the stalk. The genetic basis of morphological variations of various types of fruit trichomes in cucumber is largely unknown. The fruits of wild-type cucumber line of the tril/csgl3 mutant (completely glabrous) had types I and IV fruit trichomes (Pan et al. 2015; Cui et al. 2016; Wang et al. 2016; Fig. 2). On the other hand, the wild-type plants of the spontaneous glabrous mutant csgll set fruits with types I and II trichomes, which were changed to types VII and VIII in the mutant (Li et al. 2015; Zhao et al. 2015). Overexpression of the gene CsTTG1 that regulates fruit wart formation resulted in changes in the density of types I and II trichomes (Chen et al. 2016). Different mechanisms may be involved in the formation of different types of fruit trichomes in cucumber. More mutants of each type of fruit trichomes are needed for a better understanding

of the genes and underlying regulatory network in trichome organogenesis and development.

During the ovary stage, trichomes experienced their period of rapid development and reached a nearly mature form. At this stage, trichomes were densely covering the fruit surface as the first line of defense to protect against insect and pathogen attack. After ovary stage, trichome shape and size were maintained as relatively constant and gradually began to enter senescence phase, whereas fruit started rapid elongation and expansion. Based on our observations, senescence phase of non-glandular trichomes started from apical region to the bottom base, along with losing light green color and turning to white or brown. Since the tip cells were formed first followed by the base cells, we speculate that the order of trichome senescence should be from the top to the bottom and eventually falling off the fruit.

Plant hormones (GA, BR, ethylene, JA, SA, and CTK) and their cross talks play critical roles in various biological 
processes of plant growth including the initiation and development of plant trichomes (Greenboim-Wainberg et al. 2005; Gan et al. 2007; Pattanaik et al. 2014). In the present study, we found that cucumber fruit trichomes were influenced by GA and BAP, but the effects were concentration-dependent. The application of GA showed a positive effect on fruit trichome initiation when the concentration was below $250 \mu \mathrm{M}$ (Fig. 5a). On the other hand, BAP had a more gradual increasing effect on trichome number per fruit/ovary (Fig. 5c). Similar concentration-dependent effect of GA on trichome development was also observed in Arabidopsis (e.g., Gan et al. 2007). The differential effects of different concentrations may be related with homeostasis of the phytohormones within the plant. The involvement of GA in trichome development has been well documented by investigating Arabidopsis mutants in GA biosynthesis and signaling pathways. For example, the GA biosynthesis mutant gal-3 has glabrous leaves; trichome development of the mutant could be restored with exogenous GA application (Perazza et al. 1998). SPINDLY (SPY) is a repressor of GA signaling and the $S P Y$ mutant plant exhibited increased trichome formation (Chien and Sussex 1996; Perazza et al. 1998). Our finding that BAP acted as a positive regulator in trichome development was consistent with the early studies in Arabidopsis (e.g., Maes et al. 2008). In Arabidopsis, similar to GA, plants treated with BAP produced more trichomes per leaf, and many genes involved in trichome development or transcription factors with regulatory roles in these processes were upregulated following BAP treatment (e.g., Gan et al. 2007; Zhou et al. 2013). In Arabidopsis, likely, both GA and CTK regulate trichome formation which may be achieved through modulating the expression of key regulatory genes (e.g., Maes et al. 2008; Qi et al. 2014). Since there are some differences in trichome organogenesis and development (e.g., Liu et al. 2016), the mechanisms of phytohormones signaling on the induction of cucumber trichomes await further investigations.

\section{Conclusion}

Among 200 cucumber varieties examined, eight types of fruit trichomes (spines) were recognized. This differs from other cucumber organs with only three types of trichomes. The development of multicellular trichomes in cucumber is complex, which differs from that of unicellular trichomes, and can be classified into two groups. Moreover, the positive effect of phytohormones (GA and BAP) on fruit trichome formation is conserved in cucumber.

Author contribution statement SDX and HR conceived and designed the research. SDX, MD, and SX conducted experiments. SDX, XL, JP, and WZ analyzed the data. SDX, YW, and HR wrote the manuscript. All authors read and approved the manuscript.

Acknowledgements This work was supported by the National Natural Science Foundation of China (31830080), the National Key Research and Development Program of China (2016YFD0101705), and the Project of Beijing Agricultural Innovation Consortium (BAIC01-2017).

Open Access This article is distributed under the terms of the Creative Commons Attribution 4.0 International License (http://creativeco mmons.org/licenses/by/4.0/), which permits unrestricted use, distribution, and reproduction in any medium, provided you give appropriate credit to the original author(s) and the source, provide a link to the Creative Commons license, and indicate if changes were made.

\section{References}

Akers CP, Weybrew JA, Long RC (1978) Ultrastructure of glandular trichomes of leaves of Nicotiana tabacum L., cv Xanthi. Am J Bot 65:282-292

Ali MA, Al-Hemaid FM (2011) Taxonomic significance of trichomes micromorphology in cucurbits. Saudi J Biol Sci 18:87-92

Boughton AJ, Hoover K, Felton GW (2005) Methyl jasmonate application induces increased densities of glandular trichomes on tomato, Lycopersicon esculentum. J Chem Ecol 31:2211-2216

Chen C, Liu M, Jiang L, Liu X, Zhao J, Yan S, Yang S, Ren H, Liu R, Zhang X (2014) Transcriptome profiling reveals roles of meristem regulators and polarity genes during fruit trichome development in cucumber (Cucumis sativus L.). J Exp Bot 65:4943-4958

Chen C, Yin S, Liu X, Liu B, Yang S, Xue S, Cai Y, Black K, Liu H, Dong M, Zhang Y, Zhao B, Ren H (2016) The WD-repeat protein CsTTG1 regulates fruit wart formation through interaction with the homeodomain-leucine zipper I protein MICT. Plant Physiol 171:1156-1168

Chien JC, Sussex IM (1996) Differential regulation of trichome formation on the adaxial and abaxial leaf surfaces by gibberellins and photoperiod in Arabidopsis thaliana (L.) Heynh. Plant Physiol 111:1321-1328

Cui JY, Miao H, Ding LH, Wehner TC, Liu PN, Wang Y, Zhang SP, $\mathrm{Gu} \mathrm{XF}$ (2016) A new glabrous gene (csgl3) identified in trichome development in cucumber (Cucumis sativus L.). PLoS One 11:e0148422

Gan Y, Kumimoto R, Liu C, Ratcliffe O, Yu H, Broun P (2006) GLABROUS INFLORESCENCE STEMS modulates the regulation by gibberellins of epidermal differentiation and shoot maturation in Arabidopsis. Plant Cell 18:1383-1395

Gan Y, Liu C, Yu H, Broun P (2007) Integration of cytokinin and gibberellin signalling by Arabidopsis transcription factors GIS, ZFP8 and GIS2 in the regulation of epidermal cell fate. Development 134:2073-2081

Greenboim-Wainberg Y, Maymon I, Borochov R, Alvarez J, Olszewski N, Ori N, Eshed Y, Weiss D (2005) Cross talk between gibberellin and cytokinin: the Arabidopsis GA response inhibitor SPINDLY plays a positive role in cytokinin signaling. Plant Cell 17:92-102

Huang S, Li R, Zhang Z et al (2009) The genome of the cucumber, Cucumis sativus L. Nat Genet 41:1275-1281

Hülskamp M, Miséra S, Jürgens G (1994) Genetic dissection of trichome cell development in Arabidopsis. Cell 76:555-566 
Kang JH, Shi F, Jones AD, Marks MD, Howe GA (2010) Distortion of trichome morphology by the hairless mutation of tomato affects leaf surface chemistry. J Exp Bot 61:1053-1064

Kolb D, Muller M (2004) Light, conventional and environmental scanning electron microscopy of the trichomes of Cucurbita pepo subsp. pepo var. styriaca and histochemistry of glandular secretory products. Ann Bot 94:515-526

Li Y, Wen CL, Weng Y (2013) Fine mapping of the pleiotropic locus $B$ for black spine and orange mature fruit color in cucumber identifies a $50 \mathrm{~kb}$ region containing a R2R3-MYB transcription factor. Theor Appl Genet 126:2187-2196

Li Q, Cao C, Zhang C, Zheng S, Wang Z, Wang L, Ren Z (2015) The identification of Cucumis sativus Glabrous 1 (CsGL1) required for the formation of trichomes uncovers a novel function for the homeodomain-leucine zipper I gene. J Exp Bot 66:2515-2526

Liu X, Bartholomew E, Cai Y, Ren H (2016) Trichome-related mutants provide a new perspective on multicellular trichome initiation and development in cucumber (Cucumis sativus L). Front Plant Sci $7: 1187$

Luckwill LC (1943) The genus Lycopersicon: a historical, biological and taxonomic survey of the wild and cultivated tomatoes. Aberd Univ Stud 120:1-44

Maes L, Goossens A (2010) Hormone mediated promotion of trichome initiation in plants is conserved but utilizes species and trichome specific regulatory mechanisms. Plant Signal Behav 5:205-207

Maes L, Inze D, Goossens A (2008) Functional specialization of the TRANSPARENT TESTA GLABRA1 network allows differential hormonal control of laminal and marginal trichome initiation in Arabidopsis rosette leaves. Plant Physiol 148:1453-1464

Pan Y, Bo K, Cheng Z, Weng Y (2015) The loss-of-function GLABROUS 3 mutation in cucumber is due to LTR-retrotransposon insertion in a class IV HD-ZIP transcription factor gene CsGL3 that is epistatic over CsGL1. BMC Plant Biol 15:302

Pattanaik S, Patra B, Singh SK, Yuan L (2014) An overview of the gene regulatory network controlling trichome development in the model plant Arabidopsis. Front Plant Sci 5:259

Perazza D, Vachon G, Herzog M (1998) Gibberellins promote trichome formation by up-regulating GLABROUS1 in Arabidopsis. Plant Physiol 117:375-383

Qi T, Huang H, Wu D, Yan J, Qi Y, Song S, Xie D (2014) Arabidopsis DELLA and JAZ proteins bind the WD-repeat/bHLH/MYB complex to modulate gibberellin and jasmonate signaling synergy. Plant Cell 26:1118-1133

Qin YM, Zhu YX (2011) How cotton fibers elongate: a tale of linear cell-growth mode. Curr Opin Plant Biol 14:106-111

Samuels AL, Glass ADM, Ehret DL, Menzies JG (1993) The effect of silicon supplementation on cucumber fruit: changes in surface characteristics. Ann Bot 72:433-440

Sarria E, Palomares-Rius FJ, Lopez-Sese AI, Heredia A, GomezGuillamon ML (2010) Role of leaf glandular trichomes of melon plants in deterrence of Aphis gossypii Glover. Plant Biol 12:503-511

Serna L, Martin C (2006) Trichomes: different regulatory networks lead to convergent structures. Trends Plant Sci 11:274-280

Szymanski DB, Jilk RA, Pollock SM, Marks MD (1998) Control of GL2 expression in Arabidopsis leaves and trichomes. Development 125:1161-1171
Telfer A, Bollman KM, Poethig RS (1997) Phase change and the regulation of trichome distribution in Arabidopsis thaliana. Development 124:645-654

Tissier A (2012) Glandular trichomes: what comes after expressed sequence tags? Plant J 70:51-68

Traw MB, Bergelson J (2003) Interactive effects of jasmonic acid, salicylic acid, and gibberellin on induction of trichomes in Arabiopsis. Plant Physiol 133:1367-1375

Wagner GJ (1991) Secreting glandular trichomes-more than just hairs. Plant Physiol 96:675-679

Wang GL, Qin ZW, Zhou XY, Zhao ZY (2007) Genetic analysis and SSR markers of tuberculate trait in Cucumis sativus. Chin Bull Bot 24:168-172 (in Chinese)

Wang YL, Nie JT, Chen HM, Guo CL, Pan J, He HL, Pan JS, Cai $\mathrm{R}$ (2016) Identification and mapping of Tril, a homeodomainleucine zipper gene involved in multicellular trichome initiation in Cucumis sativus. Theor Appl Genet 129:305-316

Werker E (2000) Trichome diversity and development. Adv Bot Res 31:1-35

Yamamoto Y, Hayashi M, Kanamaru T, Watanabe T, Mametsuka S, Tanaka Y (1989) Studies on bloom on the surface of cucumber fruits, 2: relation between the degree of bloom occurrence and contents of mineral elements. Bull Fukuoka Agric Res Cent 9:1-6

Yang C, Ye Z (2013) Trichomes as models for studying plant cell differentiation. Cell Mol Life Sci 70:1937-1948

Yang F, Li L, Li M, Liu L, Ren H (2009) Genetic diversity and phylogenetic relationship of Chinese warty cucumber germplasm based on AFLPs. Acta Agric Boreal Occident Sin 18:205-211 (in Chinese)

Yang SJ, Miao H, Zhang SP, Cheng Z, Zhou J, Dong S, Wehner TC, Gu $X(2011)$ Genetic analysis and mapping of $g l-2$ gene in cucumber (Cucumis sativus L.). Acta Hortic Sin 38:1685-1692 (in Chinese)

Yang X, Zhang W, He H, Nie J, Bie B, Zhao J, Ren G, Li Y, Zhang D, Pan J, Cai R (2014) Tubercule fruit gene Tu encodes a $\mathrm{C}_{2} \mathrm{H}_{2}$ zinc finger protein that is required for the warty fruit phenotype in cucumber (Cucumis sativus L.). Plant J 78:1034-1046

Yang S, Wen C, Liu B, Cai Y, Xue S, Bartholomew ES, Dong M, Jian C, Xu S, Wang T, Qi W, Pang J, Ma D, Liu X, Ren H (2018) A CsTu-TS1 regulatory module promotes fruit tubercule formation in cucumber. Plant Biotechnol J. https://doi.org/10.1111/ pbi. 12977

Zhang H, Wang L, Zheng S, Liu Z, Wu X, Gao Z, Cao C, Li Q, Ren Z (2016) A fragment substitution in the promoter of CsHDZIV11/ CsGL3 is responsible for fruit spine density in cucumber (Cucumis sativus L.). Theor Appl Genet 129:1289-1301

Zhao JL, Pan JS, Guan Y, Zhang WW, Bie BB, Wang YL, He HL, Lian HL, Cai R (2015) Micro-trichome as a class I homeodomainleucine zipper gene regulates multicellular trichome development in Cucumis sativus. J Integr Plant Biol 57:925-935

Zhou Z, Sun L, Zhao Y, An L, Yan A, Meng X, Gan Y (2013) Zinc finger protein 6 (ZFP6) regulates trichome initiation by integrating gibberellin and cytokinin signaling in Arabidopsis thaliana. New Phytol 198:699-708 